\title{
Numerical Modelling of Erosion and Sedimentation Around Offshore Pipelines
}

\author{
F.A. VAN BEEK and H.G. WIND \\ Delft Hydraulics, De Voorst Office, P.O. Box 152, 8300 AD Emmeloord (The Netherlands) \\ Technical University of Twente, P.O. Box 217, 7500 AE Enschede (The Netherlands)
}

(Received February 7, 1989; revised and accepted July 18, 1989)

\section{ABSTRACT}

Van Beek, F.A. and Wind, H.G., 1990. Numerical modelling of erosion and sedimentation around offshore pipelines. Coastal Eng., 14: 107-128.

In this paper a numerical model is presented for the description of the erosion and sedimentation near pipelines on the sea bottom. The model is based on the Navier-Stokes equations and the equation of motion and continuity of sediment.

The results of the simulations have been compared with the results of tests in a large-scale facility. The agreement between the results of the simulations and the experimental results is good.

The applicability of the method is twofold: firstly, the processes of erosion and sedimentation around bodies on the sea bottom can be simulated; secondly, the method can be used for the design of pipelines, including erosion stimulating elements, such as spoilers.

\section{DESCRIPTION OF EROSION PROCESSES AROUND OFFSHORE PIPELINES}

\section{Introduction}

Pipelines are used inshore and offshore for the transportation of many fluids like water, oil and gas. Pipelines placed on the seabed are vulnerable for damage by fishing gear and scraping anchors. In some areas therefore it is required to protect the pipelines. This can be achieved, for instance, by covering the pipelines by trenching and subsequently backfilling of the pipeline or by using natural erosion and sedimentation processes. These natural processes can be amplified by placing a spoiler on top of the pipeline. The erosion and subsequently lowering down of the pipeline due to the natural processes can be subdivided into various stages. These will briefly be described below.

The effect of a pipeline on waves and currents is to block a part of the flow and to force the flow around the pipeline. This leads to an increase in the flow velocities upto a distance of several pipeline diameters away from the pipeline. If a pipeline is placed near the seabottom, the flow between the pipeline and 


\section{LIST OF SYMBOLS}

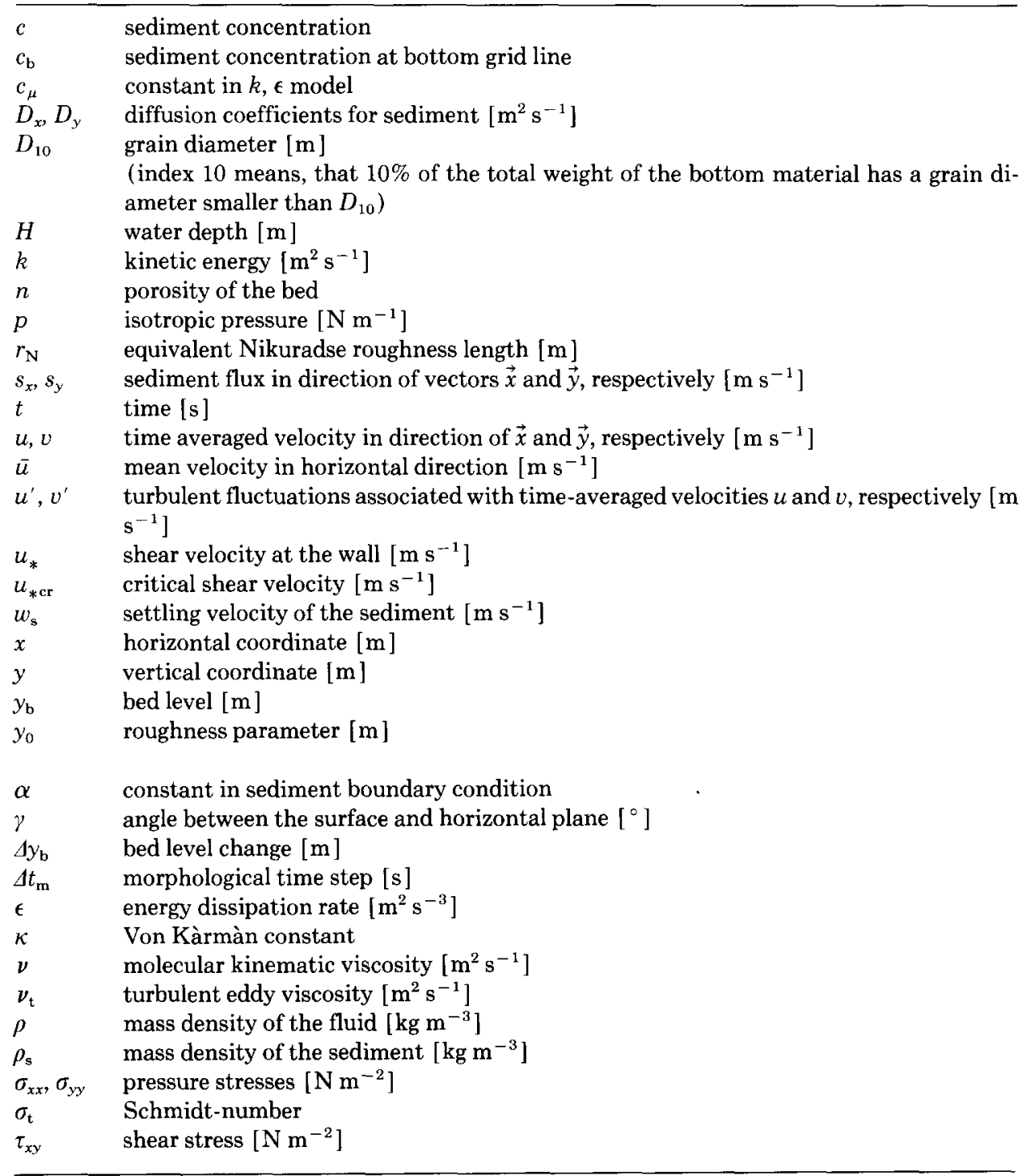

the seabottom is forced through a narrow gap, leading to even higher velocities. Together with the increase in turbulence level, locally the sediment transport capacity will also increase. This will lead to erosion in the vicinity of the pipeline. The final configuration of the scour hole depends, among others, on the 
position of the pipeline during the erosion process. For the position of the pipeline various scenarios can be envisaged, for instance:

- a fixed position of the pipeline;

- a constant distance between pipeline and seabottom;

- a prescribed displacement of the pipeline as a function of time.

If the pipeline remains in a fixed position, the increasing depth of the scourhole will lead to a reduction of the velocity near the bottom. At some stage this process will lead to an equilibrium depth. Kjeldsen et al. (1973) presented data on the maximum scour depth below pipelines in a fixed position.

If, however, the pipeline follows the erosion processes, then two effects take place simultaneously. First of all the lowering down of the pipeline leads to a reduction of the gap between pipeline and seabottom and this may lead to an decrease in flow velocity and hence sediment transport capacity, but secondary the blockage of the flow by the pipeline will lead to a reduction in the flow velocity and hence sediment transport capacity. It is expected that this dynamic lowering of the pipeline leads to a reduction of the maximum erosion depth. The effect of a spoiler will be that the blockage of the flow is enhanced and hence that the erosion is extended over a longer period, leading to an increase in scour depth.

The contribution made in this paper is that the Navier-Stokes equations, describing the turbulent flow around the pipeline and the seabed, are coupled with a dynamic description of the erodable seabed, containing both the bedload as well as the suspended sediment load. The formulas are outlined in the chapter on Mathematical formulation. Results of the computation of the erosion of the seabed caused by a fixed pipeline with and without a spoiler and a comparison with large-scale model experiments of a pipeline without spoiler are shown in the chapter on Numerical Model. This paper closes with a discussion and suggestions for further research.

\section{Various types of description of local scour}

The analyses of scour around pipelines are relatively new in engineering, compared with similar analyses of two- and three-dimensional scour around slender cylindrical piers. In the review of the state-of-the-art some cross-references to these related fields will be made.

In the 1960's and the beginning of the 1970's only experimental methods were available for the analyses of local scour near offshore pipelines. In order to generalise the results, the experimental data were presented as a function of dimensionless variables. A milestone in this respect is the work of Kjeldsen et al. (1973). Recent data of a large scale experiment are given in Bijker and Leeuwenstein (1984). These results pertain to the maximum scour depth for a fixed position of the pipeline above a sandy bottom. Another approach to the problem of local scour is the selection of field data. A problem in this case is 
that the wave and current data, the erodability of the sea bottom and the position of the pipeline relative to the sea bottom are known in a general sense, but not for the local conditions and with a limited accuracy. This makes the generalisation of this approach somewhat difficult.

A outline of the experimental research of local scour in the last decades can be found in literature surveys of Karaki and Haynie (1963), Breusers (1972), Dargahi (1982) and Clark et al. (1982). Most of the references refer to scour near bridge piers. The procedure followed in those references is that experimental and field data are gathered and represented as a function of dimensionless parameters.

Attempts to introduce analytical methods can be found in the work of Shen et al. $(1967,1969)$, where a potential flow model is used for the description of the flow field around bridge piers. By Tsujimoto and Mizukami (1985) the sediment-transport equation is elaborated and the unknown parameters are obtained from experimental results.

In the 1980's numerical approaches for the analyses of local scour and sedimentation became feasible. As far as the flow field is concerned the 1980 Stanford Conference shows a wide range of engineering applications where experimental data and numerical results converge. Initially the costs of the computations required for engineering applications are still a problem and empirical data are added to speed up solution routines. An example of such approaches is given in the SUTRENCH model of Van Rijn (1987).

Computations of local scour near a pipeline by means of a potential flow model are presented by Hansen et al. (1986). The effect of sagging velocity and three-dimensional scour has been investigated experimentally by Fredsoe et al. (1987). With the increase of the computational capabilities the borders of the applications widen. A comparison between experimental data and numerical results, using the Navier-Stokes equations coupled with a $k-\epsilon$ turbulence model, of the sediment concentration field in a flume is given by Celik and Rodi (1985). Leeuwenstein and Wind (1984) present the scour near a pipeline using the Navier-Stokes equations for the description of the flowfield. However, they only studied bedload problems.

Jensen et al. (1988) have studied the flow field around a pipeline near a fixed bottom by means of a discrete vortex model and compared the results with experimental data. From the comparison between model and experiments it follows that improvements of the flow model are required.

In the present paper the dynamic evolution of the sea bottom is added to the turbulent flow field around the pipeline. The equations describing both the flow field and the sea bottom are outlined in the next chapter.

\section{MATHEMATICAL FORMULATION}

\section{Flow field}

A detailed description of the flow pattern is a prerequisite for the calculation 
of the evolution of the scour holes. In the present example, the changes in the seabed are of the same order of magnitude as the pipe diameter, which is generally small compared with the water depth.

The basic equations describing the flow are the equations of motion and continuity in the vertical plane. The two-dimensional unsteady Navier-Stokes equations for turbulence-averaged flow in a cartesian coordinate system $(x, y)$ read:

$$
\begin{aligned}
& \frac{\partial u}{\partial t}+u \frac{\partial u}{\partial x}+v \frac{\partial u}{\partial y}+\frac{1}{\rho} \frac{\partial p}{\partial x}-\frac{1}{\rho}\left(\frac{\partial \tau_{y x}}{\partial y}+\frac{\partial \sigma_{x x}}{\partial x}\right)=0 \\
& \frac{\partial v}{\partial t}+u \frac{\partial v}{\partial x}+v \frac{\partial v}{\partial y}+\frac{1}{\rho} \frac{\partial p}{\partial y}-\frac{1}{\rho}\left(\frac{\partial \tau_{x y}}{\partial x}+\frac{\partial \sigma_{y y}}{\partial y}\right)=0
\end{aligned}
$$

where:

$$
\begin{array}{ll}
u, v & =\text { horizontal }(x) \text { and vertical }(y) \text { velocity components, } \\
& \text { respectively; } \\
\sigma_{x x}, \sigma_{y y}, \tau_{x y} & =\text { normal stresses and shear stress; } \\
\rho & =\text { mass density of the fluid; } \\
p & =\text { isotropic pressure. }
\end{array}
$$

The continuity equation reads:

$\frac{\partial u}{\partial x}+\frac{\partial v}{\partial y}=0$

The viscous and turbulent stressed in Eq. 1 are modelled using the Boussinesq hypothesis:

$$
\begin{aligned}
& \sigma_{x x}=2 \rho\left(\nu+\nu_{\mathrm{t}}\right) \frac{\partial u}{\partial x} \\
& \tau_{x y}=\rho\left(\nu+\nu_{\mathrm{t}}\right)\left(\frac{\partial u}{\partial y}+\frac{\partial v}{\partial x}\right) \\
& \sigma_{y y}=2 \rho\left(\nu+\nu_{\mathrm{t}}\right) \frac{\partial v}{\partial y}
\end{aligned}
$$

where:

$\nu=$ molecular kinematic viscosity;

$\nu_{\mathrm{t}}=$ turbulent eddy viscosity.

In the present model the turbulent eddy viscosity, $\nu_{\mathrm{t}}$, is written in terms of the turbulent kinetic energy $k$ and its dissipation rate $\epsilon$ :

$$
\nu_{\mathrm{t}}=\mathrm{c}_{\mu} \frac{k^{2}}{\epsilon}
$$


where:

$\mathrm{c}_{\mu}=$ constant with value 0.09 .

The turbulent kinetic energy, $k$, and its dissipation rate, $\epsilon$, are solved from two transport equations, forming the $k-\epsilon$ model (see Rodi, 1984 for a detailed de-

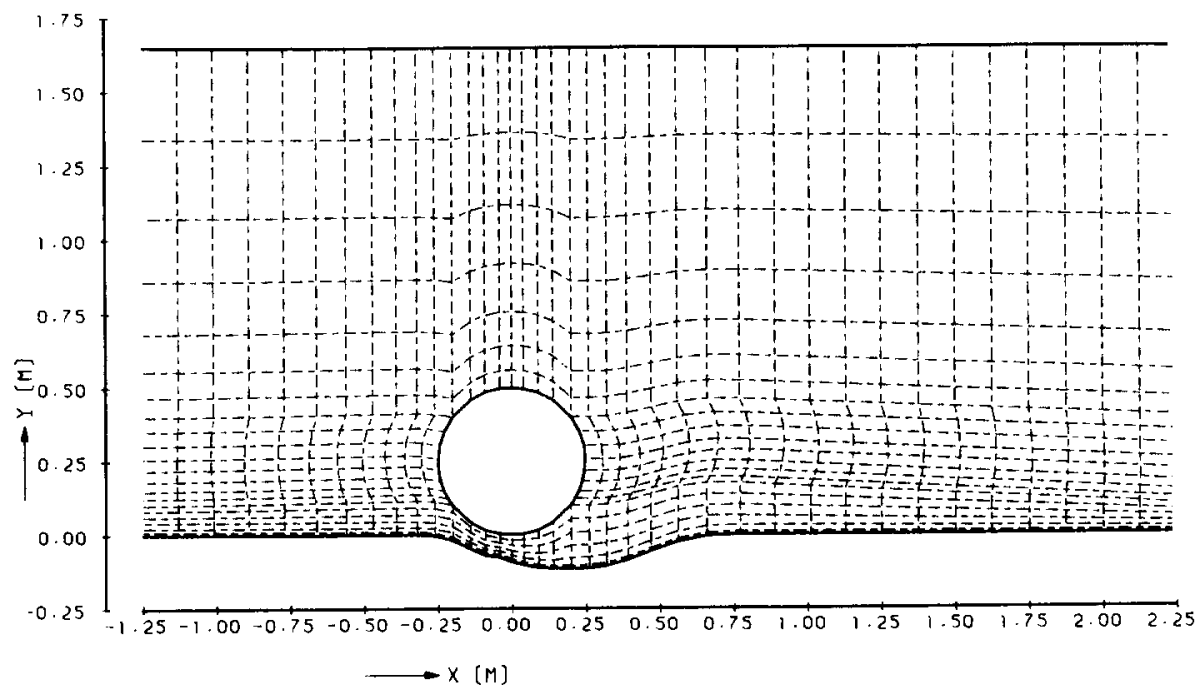

a. without spoiler

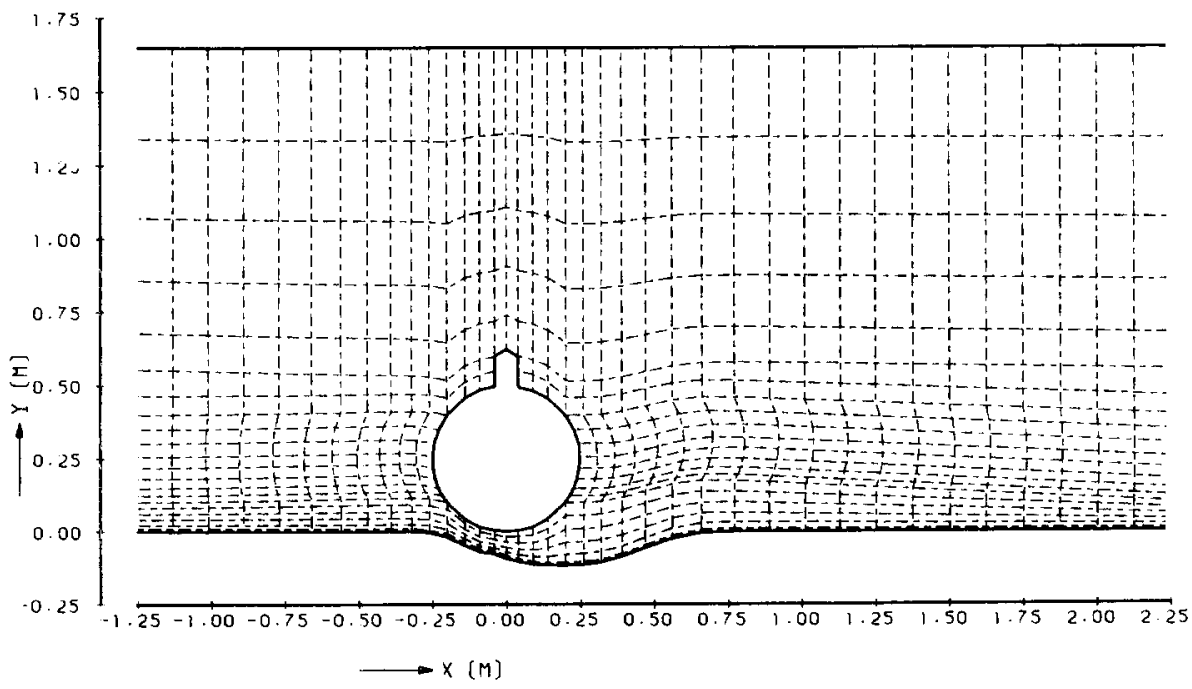

ว. with spoiler

Fig. 1. Computational grids. 
scription ). Here, values for the $k-\epsilon$ model constants are used as recommended by Launder and Spalding (1974).

In the computations presented in this paper, flow and sediment concentration in a vertical plane are simulated (Fig. 1). The upper boundary is formed by the water surface, the lower boundary is located at the bed. The watersediment mixture enters and leaves the model through the left and right boundaries, respectively.

The boundary conditions for the tangential velocity at fixed boundaries are based on the law of the wall:

$\frac{u_{\mathrm{t}}}{u_{*}}=\frac{1}{\kappa} \ln \left(\frac{y_{1}}{y_{0}}\right)$

where:

$u_{\mathrm{t}}=$ tangential velocity at distance $y_{1}$ from the wall;

$u_{*}=$ shear velocity at the wall;

$\kappa=$ Von Kàrmàn constant;

$y_{0}=r_{\mathrm{N}} / 33$

$r_{\mathrm{N}}=$ the equivalent Nikuradse roughness length;

$y_{1}=$ distance of the bottom grid line from the wall.

In addition, the normal velocity at the wall is defined equal to zero. The wall boundary conditions for $k$ and $\epsilon$ are (Rodi, 1984):

$k=\frac{u_{*}^{2}}{\sqrt{c_{\mu}}}$

$\epsilon=\frac{\left|u_{*}\right|^{2}}{\kappa y}$

A horizontal rigid lid is applied along the water surface. The pressure distribution against the lid, in fact a fixed boundary without shear, acts on the fluid in a similar way as the pressure resulting from a free surface elevation, (Alfrink, 1982). As $\nu_{\mathrm{t}}+\nu$ is non-zero at the surface, the boundary conditions for the surface become:

$w=0 \quad$ and $\frac{\partial u}{\partial y}=0$

At the upstream boundary the standard distribution functions for uniform channel flow are applied for $u, v, k$ and $\epsilon$.

\section{Sediment concentration field}

The suspended sediment concentration is described by the unsteady convection/diffusion equation: 
$\frac{\partial c}{\partial t}+u \frac{\partial c}{\partial x}+\left(v-w_{\mathrm{s}}\right) \frac{\partial c}{\partial y}-\frac{\partial}{\partial x}\left(D_{x} \frac{\partial c}{\partial x}\right)-\frac{\partial}{\partial y}\left(D_{y} \frac{\partial c}{\partial y}\right)=0$

where:

$c \quad=$ sediment concentration;

$w_{\mathrm{s}} \quad=$ settling velocity of the sediment;

$D_{x}, D_{y}=$ sediment diffusion coefficients in the $x$ and $y$ direction, respectively.

Combining Eq. 9 with the equation of continuity (Eq. 2) yields:

$\frac{\partial c}{\partial t}+\frac{\partial}{\partial x}\left(u c-D_{x} \frac{\partial c}{\partial x}\right)+\frac{\partial}{\partial y}\left\{\left(v-w_{\mathrm{s}}\right) c-D_{y} \frac{\partial c}{\partial y}\right\}=0$

The horizontal and vertical transport of sediment per unit area $\left(s_{x}\right.$ and $s_{y}$, respectively) are defined as:

$s_{x}=u c-D_{x} \frac{\partial c}{\partial x}$

$s_{y}=\left(v-w_{\mathrm{s}}\right) c-D_{y} \frac{\partial c}{\partial y}$

The diffusion coefficients $D_{x}$ and $D_{y}$ are replaced by the general diffusion coefficient for sediment $D$, related to the turbulent eddy viscosity $\nu_{\mathrm{t}}$ by:

$D=\frac{\nu_{\mathrm{t}}}{\sigma_{\mathrm{t}}}$

In principle, the Schmidt number $\sigma_{\mathrm{t}}$ varies with the flow and sediment characteristics. The influences of most of these factors are not exactly known for specific micro-scale problems. Therefore, a Schmidt number of 0.5 has been applied, as suggested by Celik and Rodi (1985).

At the water surface and at the surface of an obstacle, the flux of sediment through these surface will be zero, which implies that:

$c w_{\mathrm{s}} \cos (\gamma)-D_{\mathrm{n}} \frac{\partial c}{\partial n}=0$

where $\gamma$ is the angle between the surface and horizontal plane.

The bottom boundary condition is based on empirical entrainment relationships (Van Rijn, 1987), i.e.:

$c_{\mathrm{b}}=\alpha\left(\frac{u_{*}^{2}-u_{* \mathrm{cr}}^{2}}{u_{* \mathrm{cr}}^{2}}\right)^{1.5}$

$\alpha \quad=$ constant;

$u_{* \mathrm{cr}}=$ critical shear velocity; 
$c_{\mathrm{b}} \quad=$ sediment concentration at bottom grid line.

In this equation $c_{\mathrm{b}}$ depends only on the shear velocity. In the simulation of non-stationary conditions, however, the value of concentration $c_{2}$ in the computational point next to the bottom point can be higher than $c_{\mathrm{b}}$. In that case, diffusion will give rise to an additional flux of sediment towards the bottom $(\partial c / \partial z<0$, Eq. 11). In the computational model it is assumed for practical reasons that, at the bed, the factor $\partial c / \partial z$ in Eq. 11 should be positive or zero. This imposes $c_{2}$ as a lower limit of $c_{\mathrm{b}}$.

\section{Morphological changes}

Once the sediment concentration $c$ and the diffusion coefficient $D_{y}$ just above the bottom are known, the vertical sediment flux near the bottom can be computed from Eq. 11. According to positive or negative sediment flux the bed erodes or accretes. The rate of accration $\partial \mathrm{y}_{\mathrm{b}} / \partial t$ is given by:

$$
\frac{\partial y_{\mathrm{b}}}{\partial t}=\frac{-s_{y}}{1-n}
$$

where:

$y_{\mathrm{b}}=$ bed level;

$n=$ porosity of the bed;

$s_{y}=$ vertical sediment flux at the near bottom boundary of the computational grid.

\section{NUMERICAL MODEL}

\section{Computational procedure}

The flow chart of the morphological computations is shown in Fig. 2. It is based on a quasi-stationary approach, with the fixed bed topography during the flow computation.

In the first part of the computation, or the so-called "hydrodynamic phase", the flow and sediment concentration fields are computed. On basis of this flow field the flux of sediment "passing" the bottom boundary at each location can be calculated from Eq. 11. In the second part of the computation, the "morphological phase", this sediment flux is used to determine the topographical changes. Subsequently, the computational grid is adapted to the new topography. Once the morphological phase has been completed, the hydrodynamic phase is restarted. 


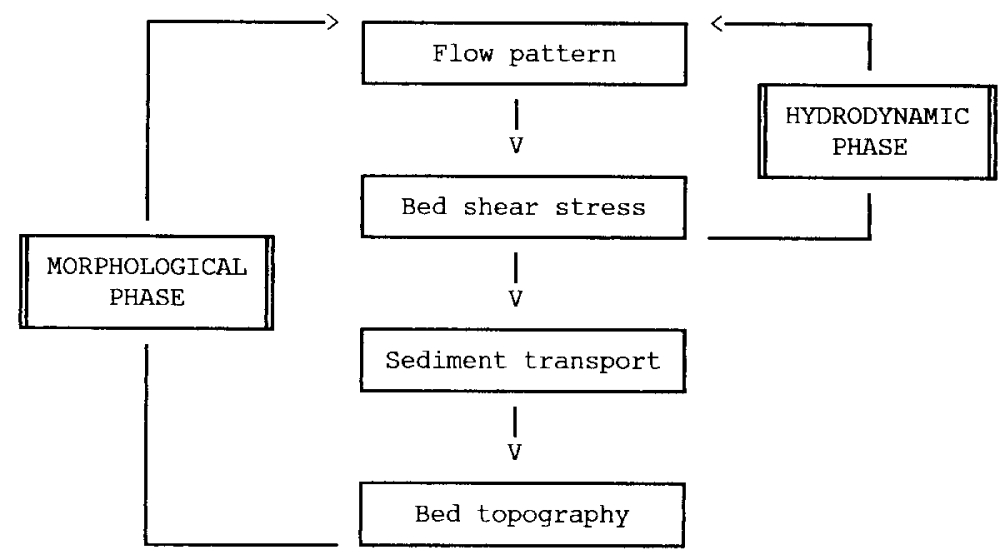

Fig. 2. Step-by-step approach.

\section{Hydrodynamic phase}

\section{Flow computation}

The flow field computation is performed with the program system ODYSSEE (Officier et al., 1984), developed for the simulation of complex two-dimensional turbulent flows. It utilizes non-orthogonal boundary-fitted curvilinear coordinates. The computational grid is multiple-connected so that flow around systems of pipes or other objects can be simulated. Local grid refinement can be applied in order to improve the resolution in areas with steep gradients, or otherwise of interest.

The numerical method is based on a fractional step technique, in which the differential equations are split according to physical phenomena (advection, diffusion, continuity correction), and solved using the method of characteristics in the advection step and finite-difference methods in the others.

Although ODYSSEE basically simulates unsteady flows, the program was used to predict steady flow fields. The time step was determined empirically, on the basis of accuracy and stability criteria. This led to $\Delta t=0.5 \mathrm{~s}$ for all flow computations.

\section{Computation of the suspended sediment concentration}

Apart from a module for the computation of the flow field and the turbulence parameter $k$ and $\epsilon$, the ODYSSEE system includes a module for the simulation of heat transport. This module could easily be extended to suspended-load sediment transport according to Eq. 10. It was run along with the flow computation, to calculate the steady concentration field as a result of a time dependent simulation. 


\section{Morphological phase}

\section{Computation of the topographical changes}

The bed level changes are computed from the explicit discretisation of Eq. 15:

$\Delta y_{\mathrm{b}}=\Delta t_{\mathrm{m}} \frac{-s_{y}}{1-n}$

where:

$\Delta y_{\mathrm{b}}=$ displacement in $y$-direction;

$\Delta t_{\mathrm{m}}=$ morphological time step.

In the initial phase of the scour hole evolution $\Delta y_{\mathrm{t}}$ is locally very large during a given time step $\Delta t_{\mathrm{m}}$. The rate of scour hole development will decrease in time, which means in the case of Eq. 16 that $\Delta y_{\mathrm{t}}$ will decrease for a given constant $\Delta t_{\mathrm{m}}$. Another elaboration of the same idea is that $\Delta t_{\mathrm{m}}$ will increase for a given constant $\Delta y_{\mathrm{b}}$. Now that the maximum value of the displacement in the $y$ direction, $\Delta y_{\mathrm{b}}$, in one morphological phase was chosen, the computed flow and sediment concentration fields did not change very much so that the next hydrodynamical computation should be stable and accurate. In this way each morphological phase delivers data for a small adaptation of the bottom boundary geometry and a value of $\Delta t_{\mathrm{m}}$ belonging to this adaptation.

\section{Grid adaptation}

The grid generation system applied makes use of the coordinates of the boundary points (Gilding, 1986). In the morphological phase the data of the old bottom-boundary geometry were replaced by the newly computed locations of the bottom boundary points. After that a new grid was generated, which was used for the computations in the next hydrodynamic phase.

\section{COMPUTATIONS OF SCOUR DEVELOPMENT}

\section{A submarine pipeline}

Erosion and/or sedimentation around pipelines can induce a natural settling of the pipelines below the seabed. One of the methods for stimulating this process, which leads to self-burial of pipelines is to mount a small spoiler on top of the pipeline. If it is possible to develop a numerical tool to predict this self-burial process, the numerical optimization of pipeline protection works (stimulated self-burial, trenching, protection by gravel, etc.) would come within reach.

In 1984, Delft Hydraulics has carried out a number of laboratory experiments (Peerbolte, 1984) to study the scour development under pipelines in prototype conditions (scale 1:1). One of these tests was selected to verify the 
present mathematical model. In this test a pipeline (diameter $0.50 \mathrm{~m}$, without spoiler) was mounted in a flume with its axis at $0.25 \mathrm{~m}$ from an erodable bed. Test runs were made with various mean flow velocities: $0.3,0.5,0.7$ and $0.9 \mathrm{~m}$ $\mathrm{s}^{-1}$. In each experiment the scour evolution was measured.

The mathematical model was applied to the experiment with the $0.7 \mathrm{~m} \mathrm{~s}^{-1}$ mean velocity. The initial bed geometry was formed by the equilibrium profile after the " $0.5 \mathrm{~m} \mathrm{~s}^{-1}$ tests". Two computations were carried out: one for a pipeline without spoiler, and the other one for a pipeline with spoiler.

\section{Boundary and initial conditions}

In the numerical simulation, the flume was assumed to be infinitely wide, so that a two-dimensional approach is possible. Figure 1 shows the initial computational grids. The bottom boundary is formed by the flume bed, the upper boundary is located at the water surface. The sediment-water mixture enters the model through the left-hand boundary and leaves the model through the right-hand boundary.

The most important input parameters are (Fig. 3):

- mean flow velocity: $\bar{u}=0.70 \mathrm{~m} \mathrm{~s}^{-1}$;

- roughness parameter: $y_{0}=0.002 \mathrm{~m}$;

- water depth: $H=1.67 \mathrm{~m}$;
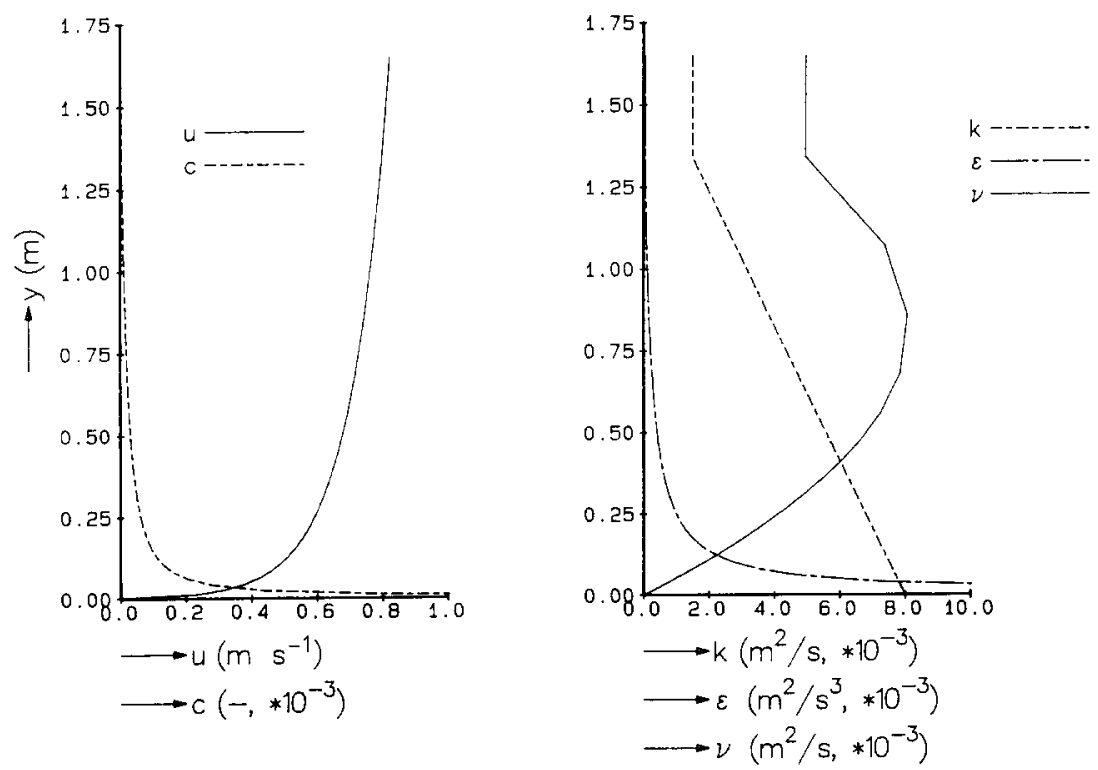

Fig. 3. Inflow boundary conditions. 
- grain size: $\mathrm{D}_{10}=0.16 \mathrm{~mm} ; D_{50}=0.22 \mathrm{~mm} ; D_{90}=0.30 \mathrm{~mm}$. So the material is fairly homogeneous. Therefore, $D_{50}$ is considered as the representative grain size;

- sediment density: $\rho_{\mathrm{s}}=2650 \mathrm{~kg} \mathrm{~m}^{-3}$;

- settling velocity: $w_{\mathrm{s}}=0.03 \mathrm{~m} \mathrm{~s}^{-1}$;

- critical shear velocity according to Shields: $u_{* \mathrm{cr}}=0.013 \mathrm{~m} \mathrm{~s}^{-1}$.

- time step: $\Delta t=0.25 \mathrm{~s}$.

- Schmidt number: $\sigma_{\mathrm{t}}=0.5$ (throughout the computational domain).

\section{Results}

Flow

Figures 4 and 5 show the flow and turbulence fields around the pipelines with and without spoiler. According to the continuity principle, it was expected that the flow velocity under the pipeline with spoiler should be about $10 \%$ higher than the flow velocity under the pipeline without spoiler. However, the simulations show a $30 \%$ higher velocity (Fig. 4). The substantial change in the hydraulic geometry by mounting a spoiler (resulting in a higher pressure drop downstream of the pipeline, Fig. 6) is blamed for this effect. Details of this phenomenon have not been studied.

Downstream of the structure the turbulence intensity is increased due to the high velocity gradients (Fig. 5), particularly if a spoiler is mounted on top of the pipeline.

\section{Sediment pick-up and transport}

In the initial part of the computations the pick-up rate below the pipeline exceeds the settling rate (Eq. 11) and hence erosion takes place. In the transport of sediment two phenomena are important, i.e. convection and diffusion. As a result of the increased turbulence intensity, the diffusion under the pipeline increases. This phenomenon is essential for keeping the sediment in suspension.

In Fig. 7 the sediment concentration fields are given. Immediately downstream of the pipeline the concentration is very high. Further downstream the turbulence intensity decreases, and hence the capacity of sediment suspension reduces. Therefore, the concentration decreases at larger distances downstream of the structure.

The effect of the variation in sediment transport capacity on the bottom geometry can be seen in Fig. 9. Below the pipeline erosion occurs, whereas downstream of the pipeline some sedimentation is found. In Fig. 10 the evolution with time of the highest and the lowest bottom points are illustrated. It follows from this figure, that the erosion and sedimentation rates decrease with time. This implies that the simulated erosion and sedimentation processes are approaching towards an equilibrium bed topography. 


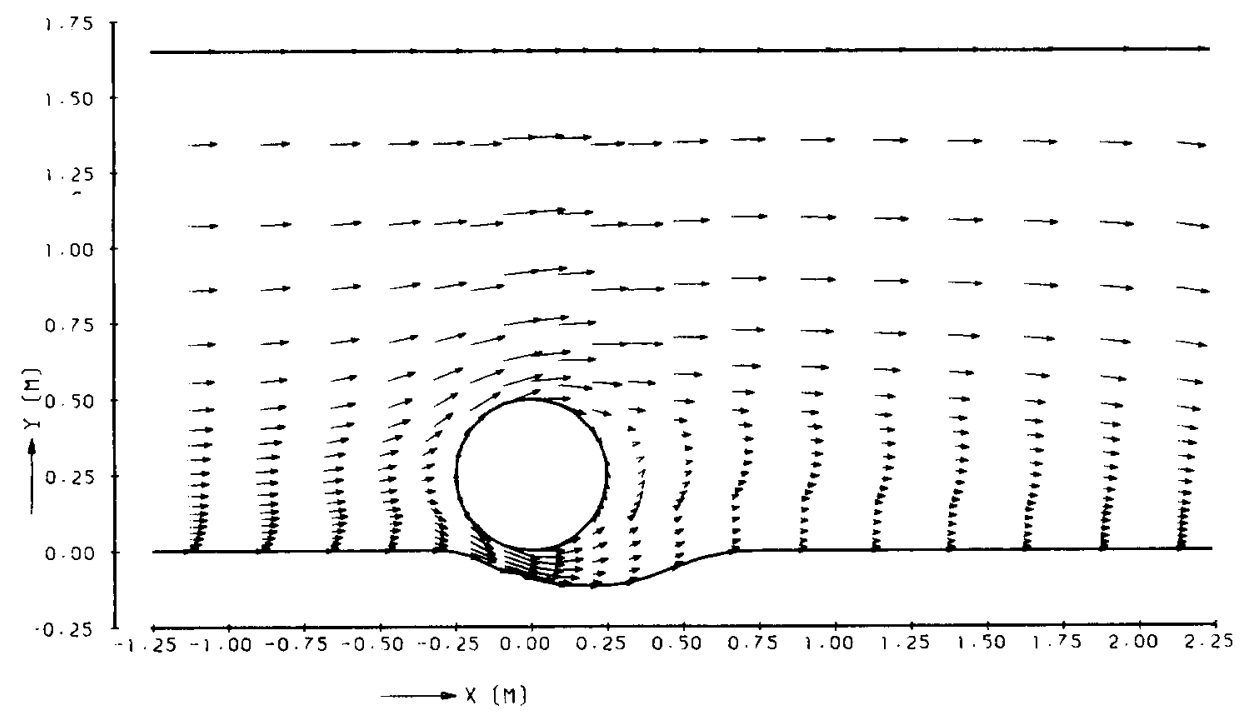

a. without spoiler

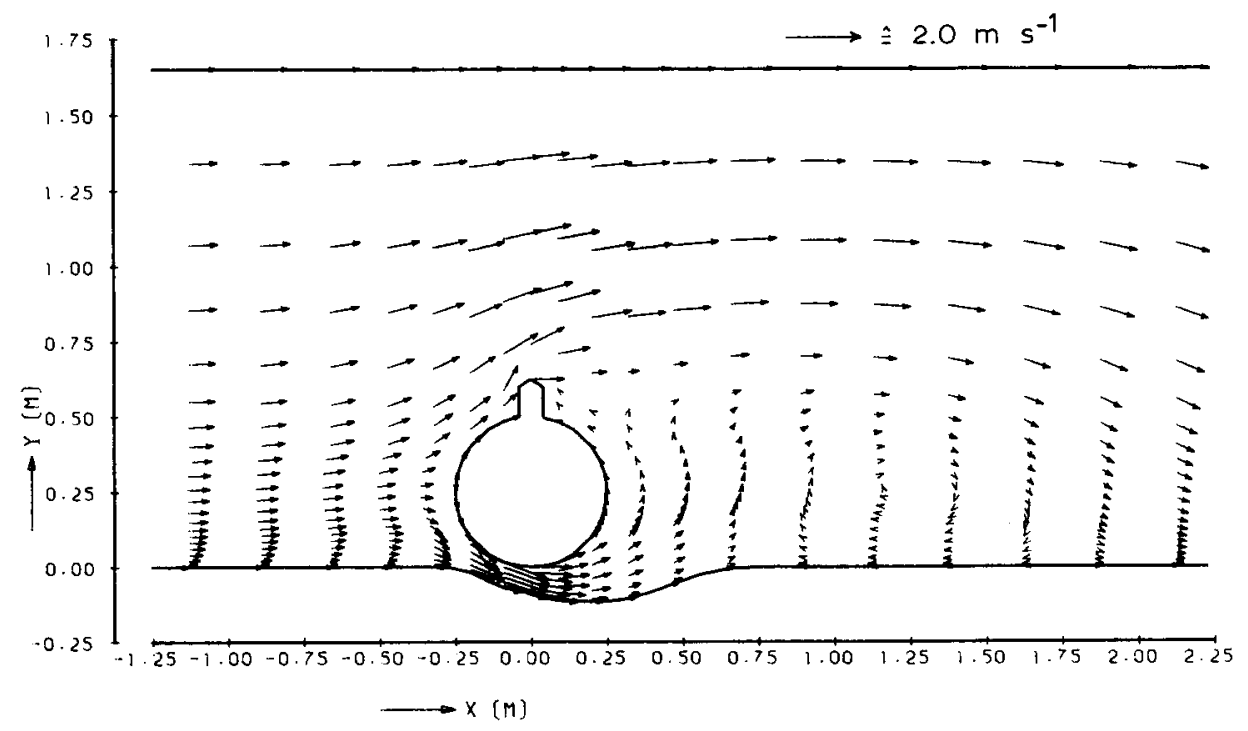

b. with spoiler

Fig. 4. Flow pattern. 


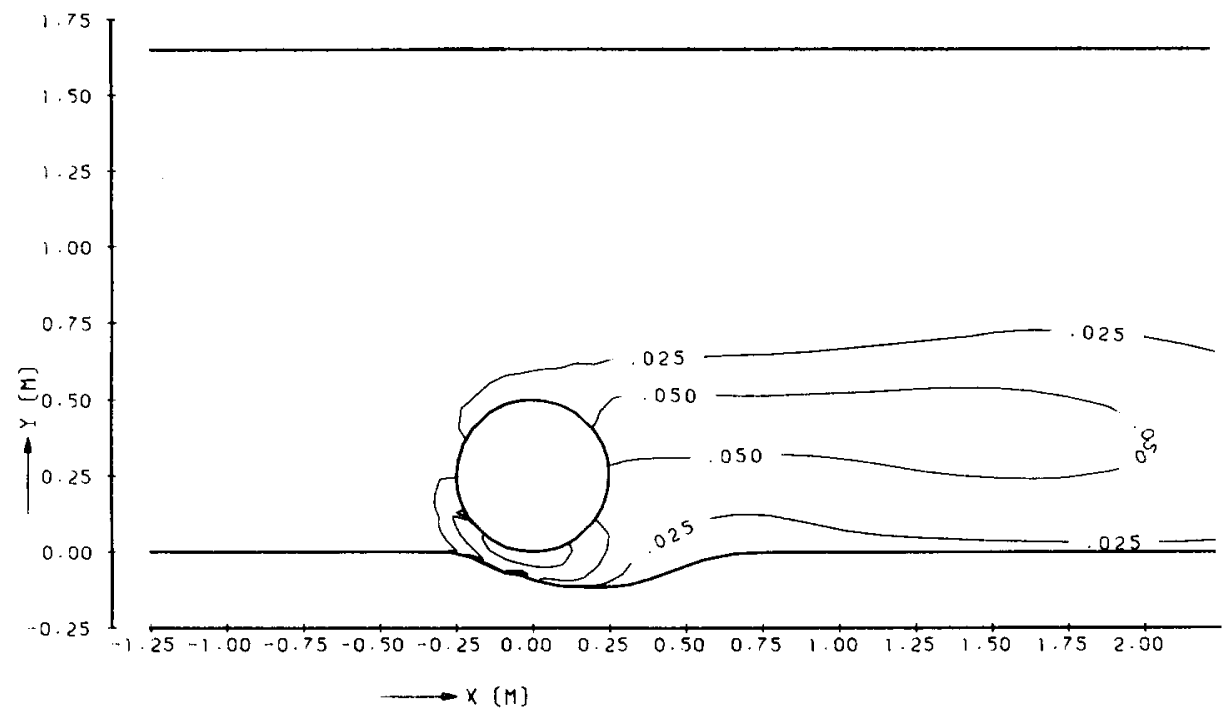

a. without spoiler

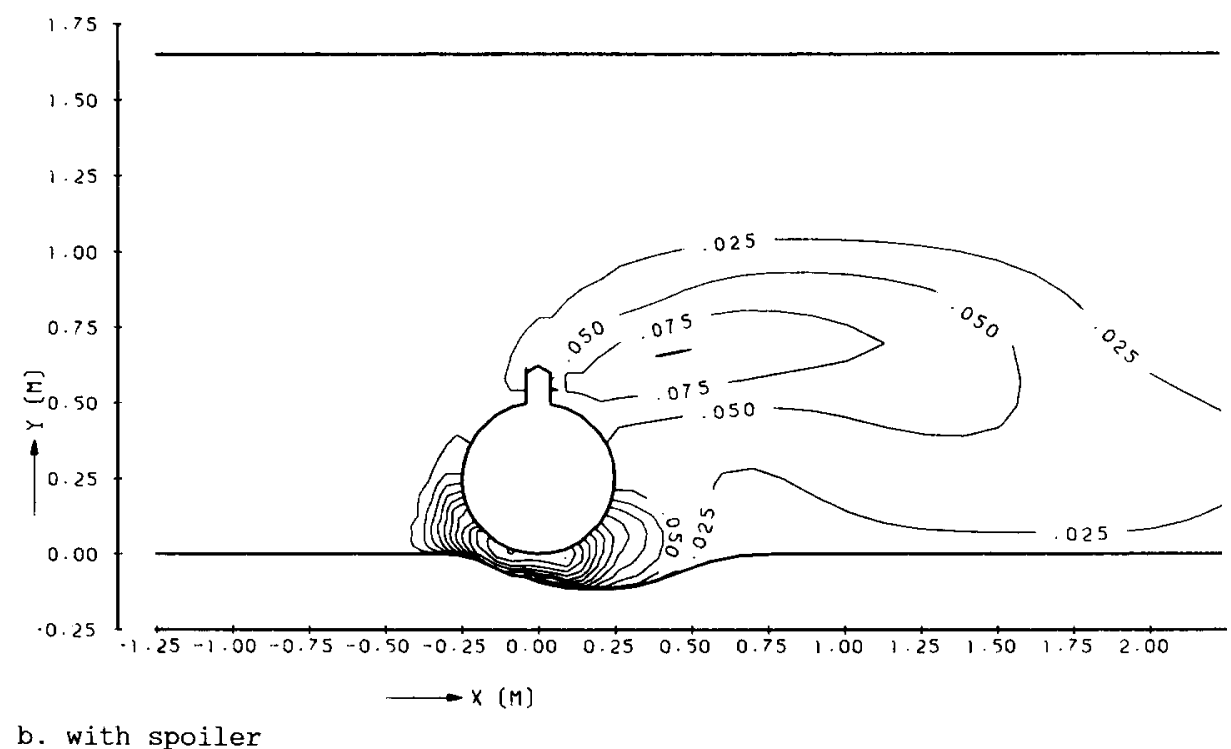

Fig. 5. Distribution of turbulent kinetic energy (interval $0.025 \mathrm{~m}^{2} \mathrm{~s}^{-1}$ ). 


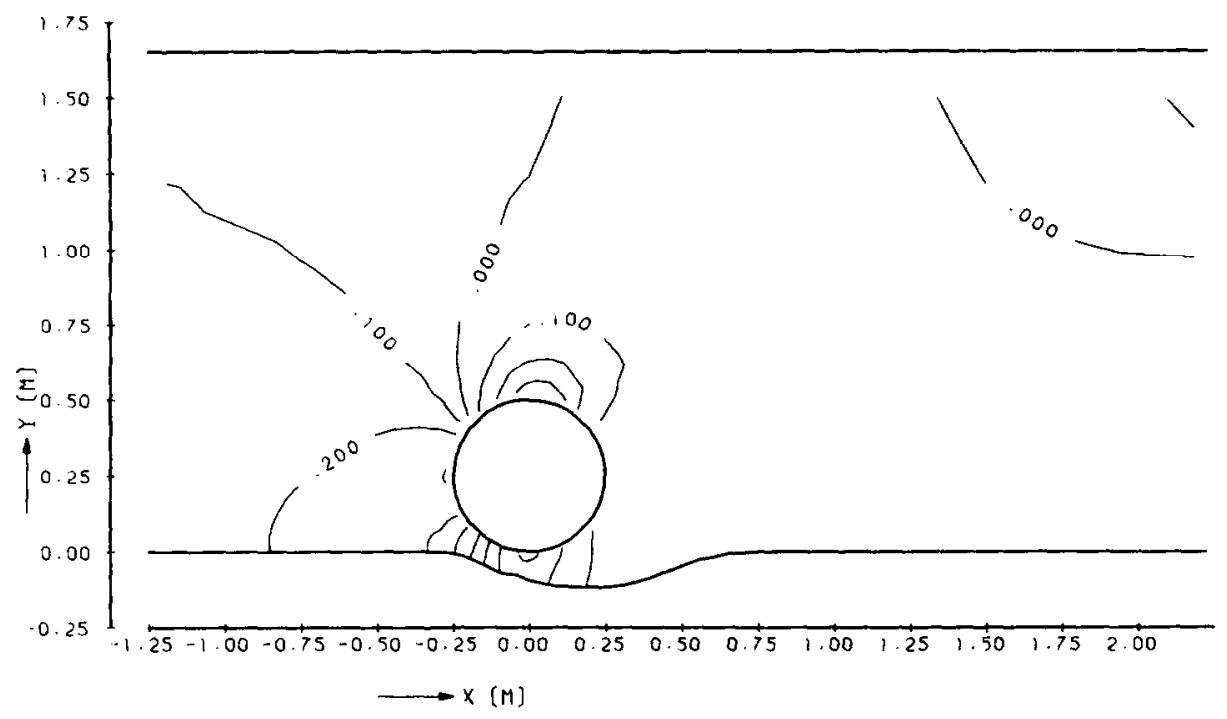

a. without spoiler

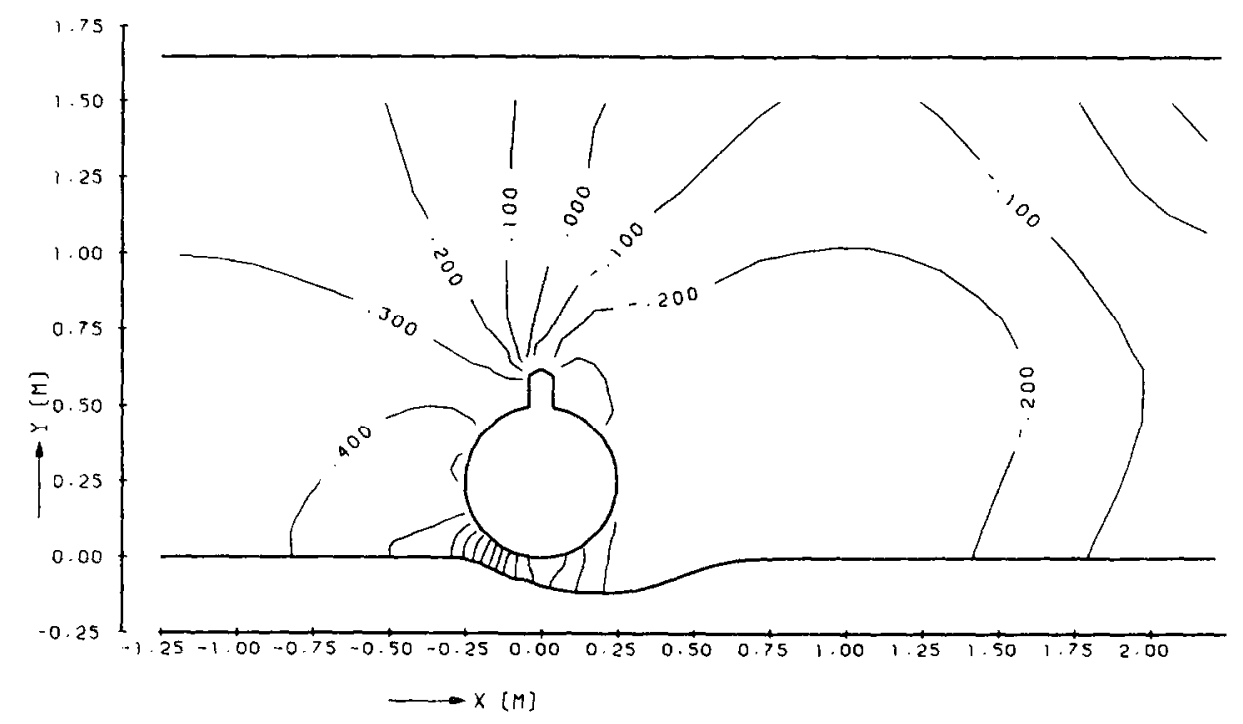

b. with spoiler

Fig. 6. Pressure distribution ( $p / p$; interval $\left.0.1 \mathrm{~m}^{2} \mathrm{~s}^{-1}\right)$. 


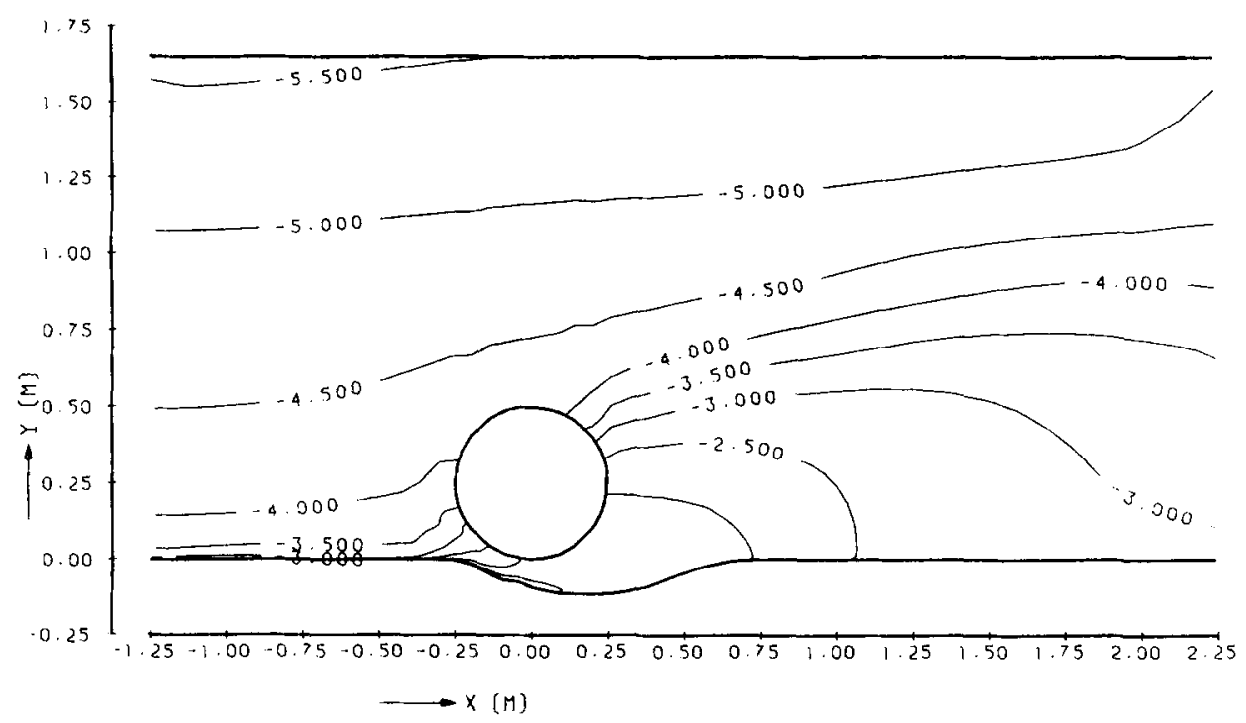

a. without spoiler

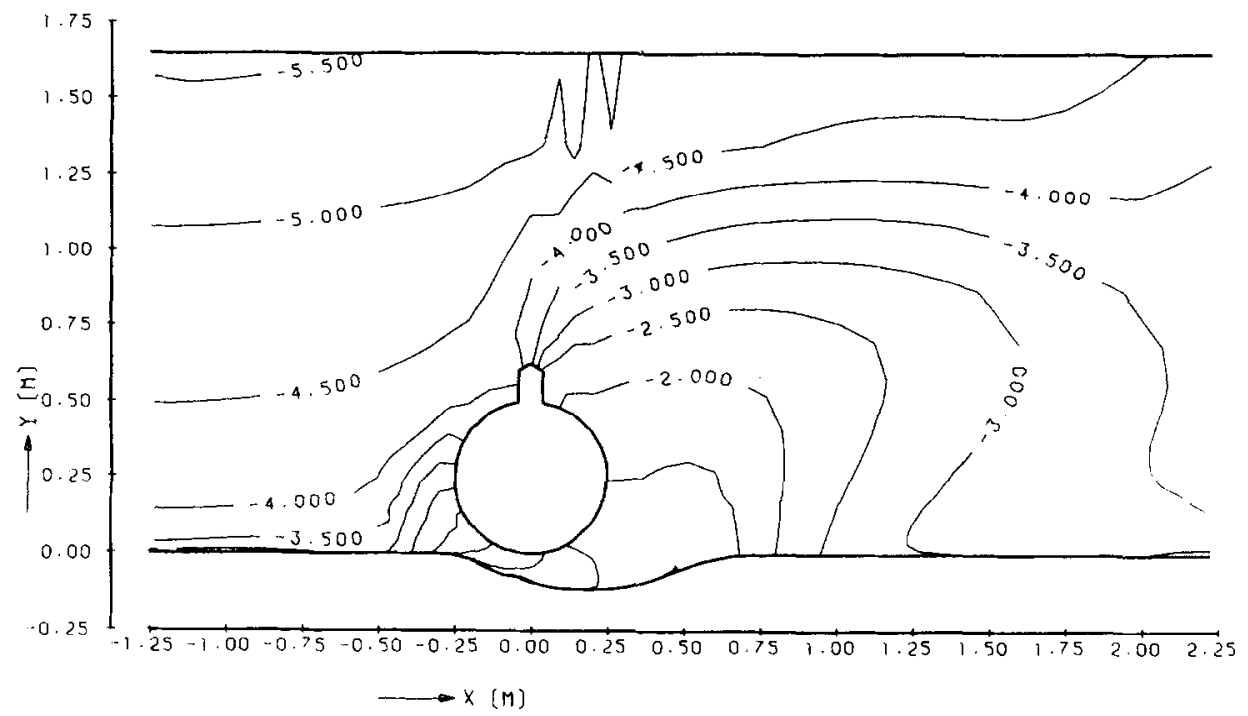

b. with spoiler

Fig. 7. Sediment concentration distribution ( $\log (c)$-isolines; interval 0.5$)$. 
$x=0.60 \mathrm{~m}$

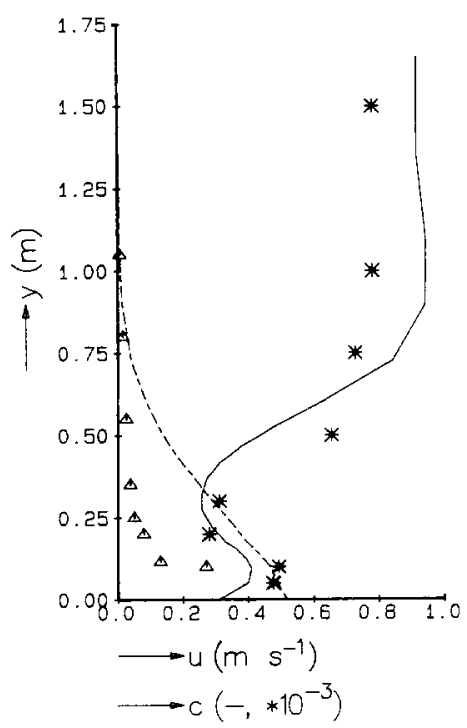

$x=1.20 \mathrm{~m}$

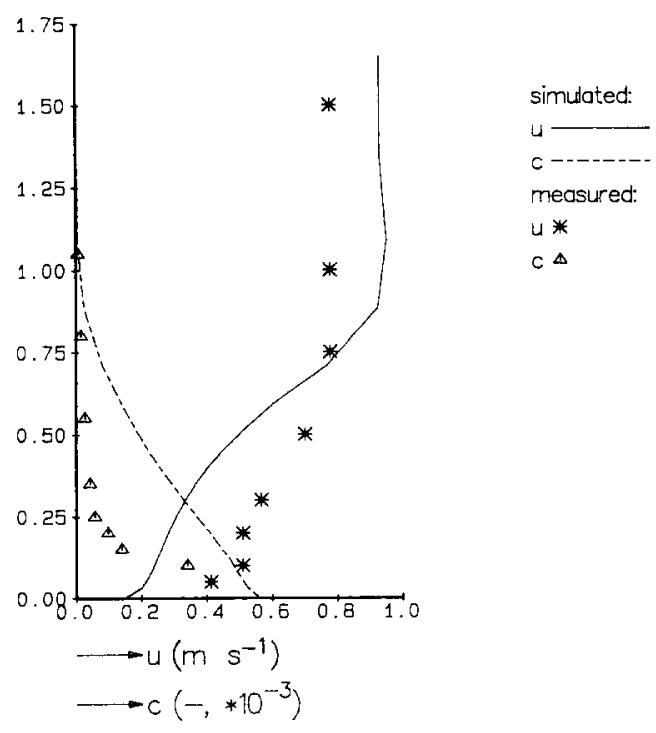

Fig. 8. Comparison of computed and measured velocities.

\section{Comparison with measurements}

The erosion and sedimentation near a pipeline without a spoiler was measured in Delft Hydraulics experiments. So, a comparison is possible. In the test in which a spoiler was applied, however, only the erosion and sedimentation were measured.

Pipeline without spoiler. Qualitatively speaking, the computed bottom geometry agrees well with the measured geometry (Fig. 9). The simulated erosion process also tends towards a maximum scour depth, which is similar to the measured depth of about $0.28 \mathrm{~m}$. This is in agreement with Kjeldsen's formula (Kjeldsen, 1973). In the computations, however, the erosion rate is three to four times as fast as the measured one. This corresponds to the observations that the computed sediment concentrations are much higher than measured (Fig. 8). This point will be discussed in the Discussion.

Pipeline with spoiler. Although the flow velocity under the pipeline with spoiler is only about $30 \%$ higher than under a pipeline without a spoiler, the erosion rate is four times as large as the case without spoiler (Fig. 10). This is in agreement with the experiments. Although the erosion rate decreases with time (Fig. 10 ), the maximum scour hole depth has not been reached. 

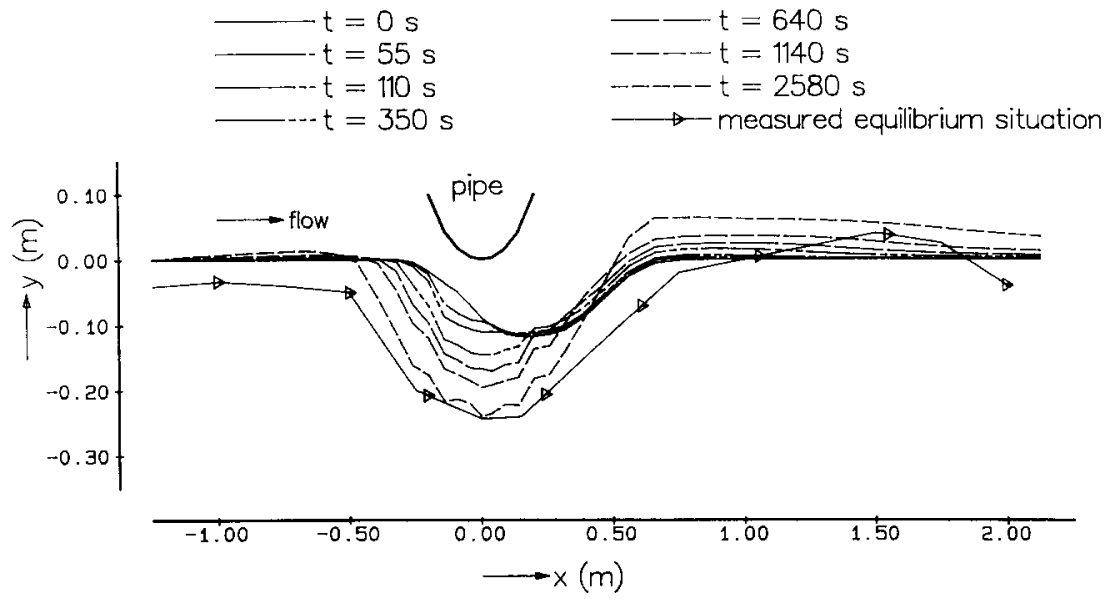

a. without spoiler
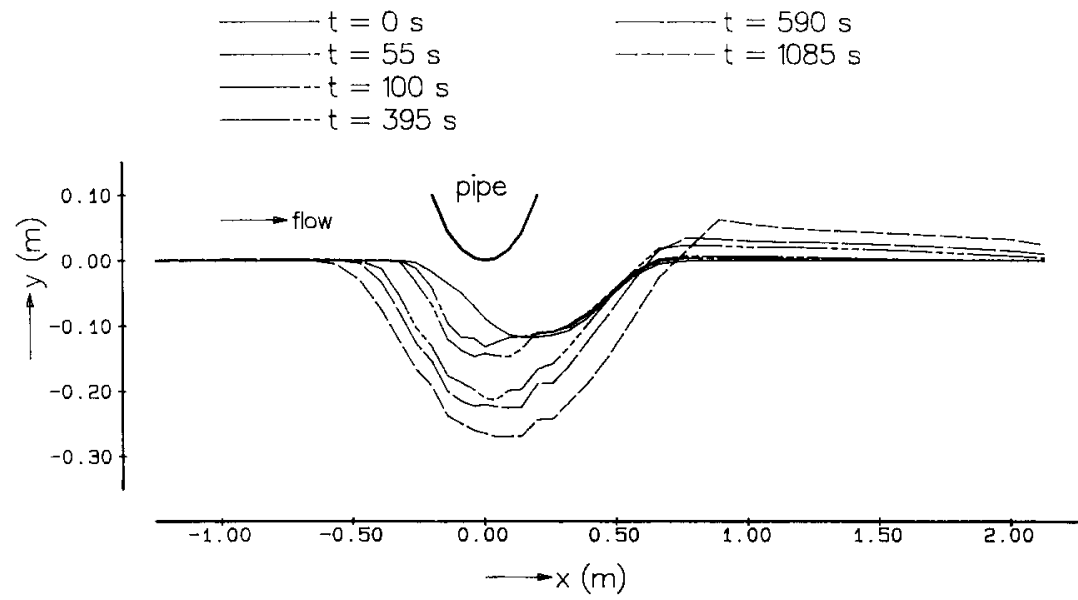

b. with spoiler

Fig. 9. Bottom geometry during erosion process.

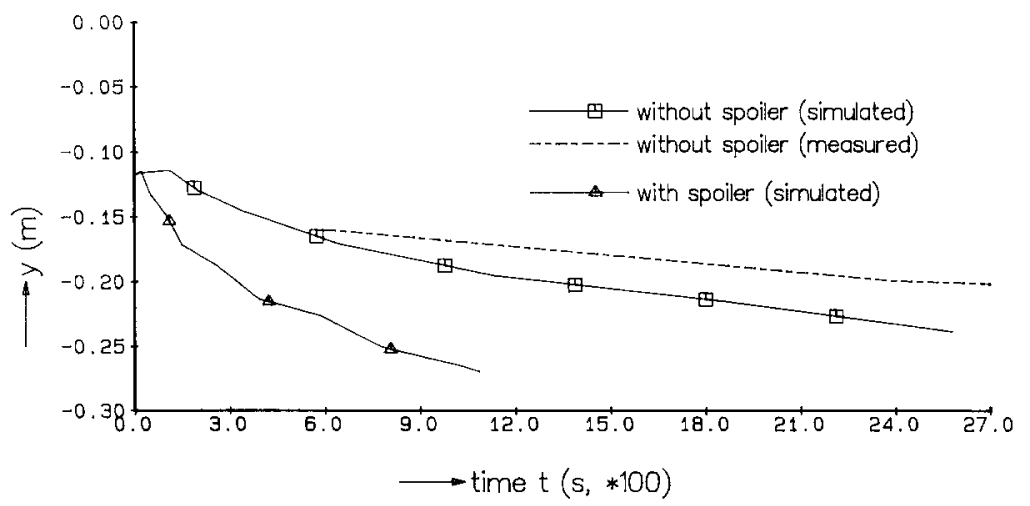

Fig. 10. Evaluation with time of highest and lowest bottom points. 


\section{DISCUSSION}

The computed maximum scour depth for a pipeline without a spoiler agrees well with the experimental data of Kjeldsen. However, the erosion time is shorter and the concentration field is higher than observed. This difference is probably caused by the fact that the bottom boundary condition (Eqs. 7, 8 and 14 ) is valid for the conditions which are homogeneous in the flow direction. This is not the case in the present problem. The non-homogeneity of the boundary layer in the flow direction can be represented by locally adapting the coefficients in the Eqs. 7, 8 and 14. However, a study of sediment transport in non-homogenous boundary layers is outside the scope of the present study.

In order to enhance the natural erosion process a spoiler can be placed upon the pipeline. In this way the blockage of the main flow continues until the scour hole is sufficiently deep to contain the pipeline.

In the experimental data much emphasis is placed upon sandy bottoms. However in many engineering applications silty sands or alternating sand and clay layers are encountered. It is expected that this will enhance in particular the time scale of the scour process. Experimental or field data related to this point are required.

In most of the research studies on the scour around offshore pipelines, the position of the pipeline relative to the original seabed is fixed. It is evisaged, that if the pipeline follows the erosion, the depth of the scour hole will be less deep than those from, for instance, the results of Kjeldsen (1973). This assumption is based upon the notion that the blockage of the main flow by the pipeline reduces with the sagging of the pipeline in the scourhole.

If the sagging of the pipeline is not continuously but intermittently, because of lateral erosion of the supports, this may lead to a sudden end of the scouring process. This will be the case if the bottom shear stress is smaller after lowering of the pipeline than immediately before the sagging process.

\section{CONCLUSIONS AND RECOMMENDATIONS}

In this paper an extention of the research of numerical morphological research towards the introduction of dynamic flexible boundaries is presented. The comparison of numerical results with experimental data shows that this line of research is promising. Some comments will be presented below.

In this paper many results obtained in specific fields much as the value of the constants in the $k-\epsilon$ equations, interaction between turbulence field and sediment concentration (Schmidt number) and sediment transport, are combined in one model. Obviously many of these results were not derived for inhomogenous flow and sediment conditions of pipelines near the seabed. In further research attention should be given to these points.

In numerical models much information is available in each reference point 
about the flowfield and sediment concentration. Combined with overall experimental data this information can inversely be used to receive more insight in the local physics and to calibrate and/or improve empirical relationships. In this respect the numerical model can act as a morphological research tool.

Mathematical as well as empirical approaches are feasible in the study on the shape of the scour hole as a function of the position of the pipeline relative to the original seabed. As some experience has been gained in the search of surfaces with a prescribed physical character, it may be useful to investigate the possibility to develop a search procedure in which scourholes are obtained for which the condition "bottom shear stress is constant" is valid. If such a search procedure is much faster than the present method, this will form an important contribution to the investigation of equilibrium scourholes beneath pipelines as a function of the position of the pipeline relative to the original seabottom.

\section{ACKNOWLEDGEMENTS}

The Netherlands Industrial Council for Oceanology (IRO) has financed research on this subject within the framework of the MaTS-programme (Netherlands Maritime Technological Research). A part of this research has been carried out at the Delft University of Technology in collaboration with the Delft Hydraulics Laboratory, amongst others, by means of model tests (M2019).

The authors wish to thank Prof. E.W. Bijker for his stimulating discussions and $W$. Leeuwenstein for his contributions in the initial stages of the research. Mr. Peerbolte has provided data in the flume experiments. Finally Dr. H.J. de Vriend is acknowledged for his comments on this paper.

\section{REFERENCES}

Alfrink, B.J., 1982. Value of refined turbulence modelling for the flow over a trench. Delft Hydraulics Publ., 268.

Breusers, H.C.N., 1972. Local scour near offshore structures. Delft Hydraulics, Publ., 105.

Bijker, E.W. and Leeuwenstein, N., 1984. Interaction between pipelines and the sea bed under the influence of waves and currents. Sea Bed Mechanics. Proc. Symp. IUTAM\&I UGG, Newcastle upon Tyne, 1983. Graham and Trotman, London, 235-242.

Celik, I. and Rodi, W., 1985. Mathematical modelling of suspended sediment transport in open channels. 21 st IAHR Congr., Melbourne.

Clark, A., Nouvak, P. and Russell, K., 1982. Local scour at slender cylindrical piers: a review and experimental analysis. Int. Symp. Engineering in Marine Environment (SEME), Brugge.

Dargahi, B., 1982. Local scour at bridge piers - a review of theory and practice. Stockholm, Bull. TRITAVBI., 114, $129 \mathrm{pp.}$

Euromech 192, 1985. Transport of suspended solids in open channels. Munich/Neubiberg, F.R. Germany. 
Fredsoe, J., Hansen, E.A., Mao, Ye and Sumer, B.M., 1987. Three-dimensional scour below pipelines. Proc. 6th Int. Symp. Offshore Mechanics and Arctic Engineering, Houston, Tex.

Gilding, B.H., 1986. A numerical grid generation technique. Comput. Fluids, 16(1): 47-58.

Hansen, E.A., Fredsoe, J. and Mao Ye, 1986. Two-dimensional scour below pipelines. 5th Int. Symp. Offshore Mechanics and Arctic Engineering, Tokyo, III: 670-677.

Jarrett, R.D. and Boyle, J.M., 1985. Pilot study for collection of bridgescour data. Water-Res. Invest. Rep. 86-4030, Denver, Colo.

Jensen, B.L., Sumer, B.M., Jensen, H.J. and Fredsoe, J., 1988. Flow around and forces on a pipeline near a scoured bed. 7th Int. Conf. Offshore Mechanics and Arctic Engineering, Houston, Tex.

Karaki, S.S. and Haynie, R.M., 1963. Mechanics of local scour part II. Bibliography prepared for U.S. Dept. Commerce Bureau of Public Roads/Div. Hydraul. Res., Contract 11-8022. Civ. Eng. Sec. Colorado State Univ. Fort Collins, Colo. (Nov. 1963).

Kjeldsen, S.P., Gjorsvik, O., Bringaker, K.G. and Jacobsen, J., 1973. Local scour near offshore pipelines. 2nd Int. Conf. Port and Ocean Engineering under Arctic Conditions, Reykjavik. Univ. Iceland, Dep. Eng. Sci., pp. 308-331.

Launder, B.E. and Spalding, D.B., 1974. The numerical computation of turbulent flow. Comp. Meth. Appl. Meci.. Ing., 3: 269.

Leeuwenstein, W. and Wind, H.G., 1984. The computation of bed shear in a numerical model. 19th Coastal Eng. Conf., Houston, Tex., pp. 1685-1702.

Mao, Y., 1987. The flow induced pipe vibration during its sagging process. East China Tech. Univ. Water Resources, Nanjing, China.

Mao, Y., 1988. Sea bed scour under pipelines. Offshore Mech. Arct. Eng., Houston, Tex.

Officier, M.J., Vreugdenhill, C.B. and Wind, H.G., 1984. Applications in hydraulics of numerical solutions of the Navier-Stokes equations. In: C. Taylor (Editor), Recent Advances in Numerical Fluid Dynamics. Pineridge Press.

Peerbolte, E.B., 1984. Self-burial of submarine pipelines; large scale model experiments in the scour due to uniform flow. Rep. Model Investigation M2019, Delft Hydraul. Lab., Delft.

Rodi, W., 1984. Turbulence models and their application in hydraulics. IAHR State-of-the-art Paper, Delft.

Shen, H.W., Schneider, V.R. and Karaki, S., 1970. Discussion of local scour around bridge piers. Proc. A.S.C.E., J. Hydraul. Div., HY7.

Shen, H.W., Schneider, V.R. and Karaki, S., 1969. Local scour around bridge piers. Proc. A.S.C.E., J. Hydraul. Div., 95, HY6.

The 1980-1981 AFOSR-HTTM-Stanford Conf. Turbulent Flows, 1980. Comparison of Computations and Experiments, Proceedings.

Tsujimoto, T. and Mizukami, T., 1985. Analytical approach to local scour around a bridge pier with continuous sediment motion. Mem. Fac. Tech. Kanazana Univ.

Van Rijn, L.C., 1982. The Computation of Bed-load and Suspended Load Transport. Report S487II, Delft Hydraulics Laboratory, Delft.

Van Rijn, L.C., 1987. Mathematical modelling of morphological processes in the case of suspended sediment transport. Delft Hydraul. Commun., 382.

Wind, H.G. and Leeuwenstein, W., 1984. The computation of bed shear in a numerical model. 19th Int. Conf. Coastal Engineering, Houston, Tex. 